\title{
Simultaneous Determination of Urine Methotrexate, 7-Hydroxy Methotrexate, Deoxyaminopteroic Acid, and 7-Hydroxy Deoxyaminopteroic Acid by UHPLC-MS/MS in Patients Receiving High-dose Methotrexate Therapy
}

\author{
Shenghui MeI, ${ }^{*}, *$ Yong CuI, ${ }^{* * *}$ Dongjie Zhang, ${ }^{*}$ Chun Zeng, ${ }^{* * *}$ Xiaohui Ren, ${ }^{* * *}$ Kefu Yu, ${ }^{*}, * *$ \\ Song LIN, ${ }^{* * * \dagger}$ and Zhigang ZHAO ${ }^{*}, * * \dagger$ \\ *Department of Pharmacy, Beijing Tiantan Hospital, Capital Medical University, 119 Nansihuan West Road, \\ Fengtai District, Beijing 100070, P. R. China \\ **Department of Clinical Pharmacology, College of Pharmaceutical Sciences, Capital Medical University, \\ Beijing 100045, P. R. China \\ ***Department of Neurosurgery, Beijing Tiantan Hospital, Capital Medical University, 119 Nansihuan West Road, \\ Fengtai District, Beijing 100070, P. R. China
}

\begin{abstract}
Nephrotoxicity, the most important toxicity in high-dose methotrexate (MTX) therapy, is partly caused by the formation of crystal deposits in the kidney due to poor water solubility of MTX and its metabolites 7-hydroxy methotrexate (7-OH MTX), deoxyaminopteroic acid (DAMPA) and 7-hydroxy deoxyaminopteroic acid (7-OH DAMPA). Plasma MTX levelguided urine alkalinization, leucovorin rescue and glucarpidase detoxification are common strategies to overcome MTXrelated nephrotoxicity. However, overestimation is a problem for MTX analysis by immunoassays due to the crossreactivity of MTX metabolites (7-OH MTX and DAMPA). An UHPLC-MS/MS method for the simultaneous determination of MTX, 7-OH MTX, DAMPA and 7-OH DAMPA in human urine was developed, validated and applied in clinical practice. Samples were treated by one-step protein precipitation and analyzed within 3 min. The calibration range was 0.02 to $4 \mu \mathrm{mol} / \mathrm{L}$ for MTX and DAMPA, and 0.1 to $20 \mu \mathrm{mol} / \mathrm{L}$ for 7-OH MTX and 7-OH DAMPA. For all analytes, the intra-day and inter-day bias and imprecision were -8.0 to 7.6 and $<9.0 \%$, the internal standard normalized recovery and matrix factor were 92.34 to 109.49 and $<20.68 \%$. The plasma MTX and 7-OH MTX levels increased with the urine drug levels, age, serum creatinine and alanine transaminase, but urine could not replace blood for MTX monitoring due to their poor correlation $\left(R^{2}, 0.16\right.$ to 0.51$)$. Dose-normalized urine and plasma MTX and 7-OH MTX levels were similar between different patient groups (urine $\mathrm{pH}<7$ or $\geq 7$ ). Due to the large inter-individual variance of the analytes levels in both plasma and urine, these findings should be treated with caution.
\end{abstract}

Keywords UHPLC-MS/MS, urine, methotrexate, 7-hydroxy methotrexate, deoxyaminopteroic acid, 7-hydroxy deoxyaminopteroic acid, method development and validation

(Received December 23, 2019; Accepted August 6, 2020; Advance Publication Released Online by J-STAGE August 14, 2020)

\section{Introduction}

MTX is widely used for cancer treatment, such as acute lymphoblastic leukemia, osteosarcoma and primary central nervous system lymphoma. ${ }^{1}$ The major problem for high-dose MTX therapy is life-threatening toxicities, especially nephrotoxicity, ${ }^{1}$ which is partly caused by the formation of crystal deposits in the kidney due to the poor water solubility of MTX and its metabolites 7-hydroxy methotrexate (7-OH MTX), deoxyaminopteroic acid (DAMPA) and 7-hydroxy deoxyaminopteroic acid (7-OH DAMPA) under acid conditions. ${ }^{1-6}$ Under alkaline conditions, the water solubility of MTX and its metabolites dramatically increases because their carboxylic acid groups are transformed into carboxylate ions. Therefore urine

S. M. and Y. C. contributed equally to this work.

† To whom correspondence should be addressed.

E-mail: linsong2005@126.com (S. L.); ttyyzzg1022@126.com (Z.Z.) alkalinization, in combination with MTX monitoring-guided glucarpidase detoxification and leucovorin rescue, are routine strategies to overcome MTX-induced toxicities. ${ }^{1,7}$

In clinical studies, urine alkalinization increases MTX clearance and decreases high-dose MTX-induced toxicities. ${ }^{8,9}$ However, over-alkalinization increases the risk of acid-base disturbance. A study found that a reduction of the urine $\mathrm{pH}$ threshold from 8 to 7 did not affect the clearance of MTX, the rates of nephrotoxicity and the length of hospital stay. ${ }^{10}$ Therefore, urine $\mathrm{pH}$ is routinely monitored for alkalinization adjustment. Glucarpidase, an efficient drug for MTX detoxification, can rapidly and completely transform MTX into its inactive form, DAMPA, which can form crystal deposits in the urine due to its poor water solubility. ${ }^{4,7}$ Therefore the urine level of DAMPA is recommended to monitor in patients receiving glucarpidase therapy. ${ }^{4}$

Predicting MTX-induced toxicities is a challenge for clinicians due to huge intra- and inter-individual variances of the MTX pharmacokinetics and pharmacodynamics. ${ }^{1,2,5,11}$ Therefore, 
MTX plasma level is routinely monitored in clinical practice for leucovorin dose adjustments, especially in patients receiving high-dose MTX therapy. Immunoassays are widely used methods for MTX monitoring with significant overestimations, especially at low levels due to cross-reactivity caused by MTX metabolites (7-OH MTX, DAMPA, and 7-OH DAMPA), which have similar chemical structures with MTX.,25,12,13 Various chromatographic based assays have been developed for MTX, 7-OH MTX and DAMPA analysis in human blood plasma, ${ }^{2,3,5,13-26}$ but these methods have some disadvantages, such as the timeconsuming procedure for sample pretreatment ${ }^{15,16}$ and a long turnaround time (5 to $60 \mathrm{~min}$ )., ${ }^{2,3,15,17,21}$ MTX is mainly excreted in the urine, which is more convenient to obtain compared to blood, especially for children; therefore, urine is potential to replace blood for MTX monitoring. However, only two methods were developed for MTX analysis in human urine. ${ }^{23,24}$ One method analyzed MTX by using a high sample volume $(500 \mu \mathrm{L})$ and a low upper limit of detection $(0.11 \mu \mathrm{mol} / \mathrm{L}),{ }^{23}$ the other analyzed MTX and 7-OH MTX with a long turnaround time $(6.6 \mathrm{~min}) .^{24}$

This study was aimed to develop and validate a fast, accurate, and robust ultra high-performance liquid-chromatography tandem mass/mass spectrometry (UHPLC-MS/MS) method for the simultaneous determination of MTX, 7-OH MTX, DAMPA, and 7-OH DAMPA in human urine, and to apply it in patients with primary central nervous system lymphoma receiving highdose MTX therapy. The influence of urine $\mathrm{pH}$ on plasma and urine MTX and 7-OH MTX levels was established and the correlation between the plasma and urine levels of both MTX and 7-OH MTX was evaluated to find out whether urine could replace blood for monitoring.

\section{Experimental}

\section{Reagents and chemicals}

MTX (Lot: 100138-201606, 99.8\% purity) was obtained from the National Institutes for Food and Drug Control (Beijing, China). 7-OH MTX (Lot: 11-NSR-30-2, 95.23\% purity), DAMPA (Lot: 1-JMS-61-4, 96\% purity), 7-OH DAMPA (Lot: 10-JHY-49-2, 95\% purity), MTX-D (Lot: 12-ZCA-5-1, 95\% purity, $99.0 \%$ isotopic purity, internal standard, IS), and DAMPA-D $_{3}$ (Lot: 1-TEK-173-1, 95\% purity, 98.5\% isotopic purity, IS) were purchased from the Toronto Research Chemicals INC (Toronto, Canada). Methanol and formic acid were purchased from Fisher Scientific (Waltham, USA), while ultrapure water was generated from a Millipore Ultra pure water system (Bedford, USA). Analytes- and IS-free urine were obtained from healthy volunteers and checked to ensure they did not contain any of the analytes and IS.

\section{Instrumentations}

An Acquity UHPLC H-Class (Waters, MA, USA) tandem 5500 QTRAP mass system (AB SCIEX, CA, USA) was used for analysis. Data was acquired and processed by using Analyst software (AB SCIEX, CA, USA, Ver. 1.6).

\section{$L C$ and MS conditions}

A BEH C18 column (Waters, $2.1 \times 50 \mathrm{~mm}, 1.7 \mu \mathrm{m}$ particles) was used for separation by using methanol (A, $0.1 \%$ formic acid) and water (B, contain 5\% methanol, $0.1 \%$ formic acid) as mobile phase with a flow rate of $0.4 \mathrm{~mL} / \mathrm{min}$ under gradient elution as follows: initial, 5.5\% A; $0-1.0 \mathrm{~min}, 5.5 \% \mathrm{~A}-90 \% \mathrm{~A}$; 1.0 - $1.6 \mathrm{~min}, 90 \% \mathrm{~A} ; 1.6-1.7 \mathrm{~min}, 90 \% \mathrm{~A}-5.5 \% \mathrm{~A} ; 1.7-$ $3.0 \mathrm{~min}, 5.5 \%$ A (1.3 min for equilibration). The autosampler and column oven were set at 10 and $37^{\circ} \mathrm{C}$.

Positive electrospray ionization was performed at $550^{\circ} \mathrm{C}$ with an ion spray voltage of $5500 \mathrm{~V}$. Curtain gas, ion source gas 1 , and ion source gas 2 were set at 35,55 , and 55 psi, respectively. Medium collision gas was used. The quantitative and qualitative ion pairs, ion collision energy, declustering potential, entrance potential, and collision cell exit potential are given in Table S1 (Supporting Information). The chemical structure and mass spectrometry of analytes and IS are shown in Fig. 1.

\section{Preparation of stock and working solutions}

MTX $(4000 \mu \mathrm{mol} / \mathrm{L}), 7-\mathrm{OH}$ MTX $(2000 \mu \mathrm{mol} / \mathrm{L})$, DAMPA $(4000 \mu \mathrm{mol} / \mathrm{L}), \quad 7-\mathrm{OH} \quad$ DAMPA $\quad(2000 \mu \mathrm{mol} / \mathrm{L}), \quad \mathrm{MTX}^{-D_{3}}$ $(220 \mu \mathrm{mol} / \mathrm{L})$, and DAMPA-D $3(300 \mu \mathrm{mol} / \mathrm{L})$ were dissolved in ultrapure water containing $16 \mathrm{mmol} / \mathrm{L} \mathrm{NaOH}$ (for dissolution). The four analytes were mixed together to obtain a series of working solutions of calibrators at $0.02,0.04,0.2,0.4,2$, and $4 \mu \mathrm{mol} / \mathrm{L}$ for MTX and DAMPA, and $0.1,0.2,1,2,10$, and $20 \mu \mathrm{mol} / \mathrm{L}$ for 7-OH MTX and 7-OH DAMPA. The two IS were also mixed together at $0.1 \mu \mathrm{mol} / \mathrm{L}$ for $\mathrm{MTX}^{-\mathrm{D}_{3}}$ and $0.2 \mu \mathrm{mol} / \mathrm{L}$ for DAMPA- $\mathrm{D}_{3}$. The working solutions of QC samples were $0.02,0.06,0.12,1.8$, and $3 \mu \mathrm{mol} / \mathrm{L}$ for MTX and DAMPA, and $0.1,0.3,0.6,9$, and $15 \mu \mathrm{mol} / \mathrm{L}$ for $7-\mathrm{OH}$ MTX and 7-OH DAMPA. All stock and working solutions were stored at $-80^{\circ} \mathrm{C}$ before use.

\section{Preparation of calibration and quality control $(Q C)$ samples}

Ten $\mu \mathrm{L}$ of analytes- and IS-free urine were mixed with $10 \mu \mathrm{L}$ of a working solution and $10 \mu \mathrm{L}$ of IS (contain $0.1 \mu \mathrm{mol} / \mathrm{L}$ MTX-D ${ }_{3}$ and $0.2 \mu \mathrm{mol} / \mathrm{L}$ DAMPA-D $)_{3}$; then, $300 \mu \mathrm{L}$ of methanol (with $15 \%$ water and $0.1 \%$ formic acid) was added for protein precipitation and extraction. After 5-min vortex mixing, 30 -min storage at $4^{\circ} \mathrm{C}$, and 2-min centrifugation at $12000 \times g$, $2 \mu \mathrm{L}$ of the supernatant was injected for analysis. A series of calibration samples at $0.02,0.04,0.2,0.4,2$, and $4 \mu \mathrm{mol} / \mathrm{L}$ for MTX and DAMPA, and $0.1,0.2,1,2,10$, and $20 \mu \mathrm{mol} / \mathrm{L}$ for 7-OH MTX and 7-OH DAMPA, and QC samples at 0.02, 0.06, $0.12,1.8$, and $3 \mu \mathrm{mol} / \mathrm{L}$ for MTX and DAMPA, and 0.1, 0.3, $0.6,9$, and $15 \mu \mathrm{mol} / \mathrm{L}$ for 7-OH MTX and 7-OH DAMPA were prepared.

\section{Sample collection and preparation}

Patients with primary central nervous system lymphoma receiving high-dose MTX therapy were enrolled. Then, $1 \mathrm{~mL}$ of venous blood was collected at about 13,37 , and $61 \mathrm{~h}$ after infusion, and $1 \mathrm{~mL}$ of urine was obtained from the patients' natural urine at similar time points. For urine, after 5-min centrifugation at $3000 \times g, 10 \mu \mathrm{L}$ of urine was spiked with $10 \mu \mathrm{L}$ of IS (contain $0.1 \mu \mathrm{mol} / \mathrm{L}$ MTX-D ${ }_{3}$ and $0.2 \mu \mathrm{mol} / \mathrm{L}$ DAMPA- $\mathrm{D}_{3}$ ) and $10 \mu \mathrm{L}$ of water containing $16 \mathrm{mmol} / \mathrm{L} \mathrm{NaOH}$ (for dissolution); then, $300 \mu \mathrm{L}$ of methanol (containing $15 \%$ water and $0.1 \%$ formic acid) was added for protein precipitation. After 5-min vortex mixing, 30-min storing at $4^{\circ} \mathrm{C}$, and 2-min centrifugation at $12000 \times g, 2 \mu \mathrm{L}$ of the supernatant was injected for analysis. The final concentration of IS was $0.003 \mu \mathrm{mol} / \mathrm{L}$ for $\mathrm{MTX}-\mathrm{D}_{3}$ and $0.006 \mu \mathrm{mol} / \mathrm{L}$ for DAMPA- $\mathrm{D}_{3}$. The plasma MTX and 7-OH MTX levels were determined by our previously validated LC-MS/MS method. ${ }^{22}$

\section{Method validation}

Method validation was performed according to the guidelines including the selectivity, carry-over, lower limit of quantitation (LLOQ), calibration curve, accuracy, precision, dilution integrity, recovery, matrix effect, and stability. 27,28 

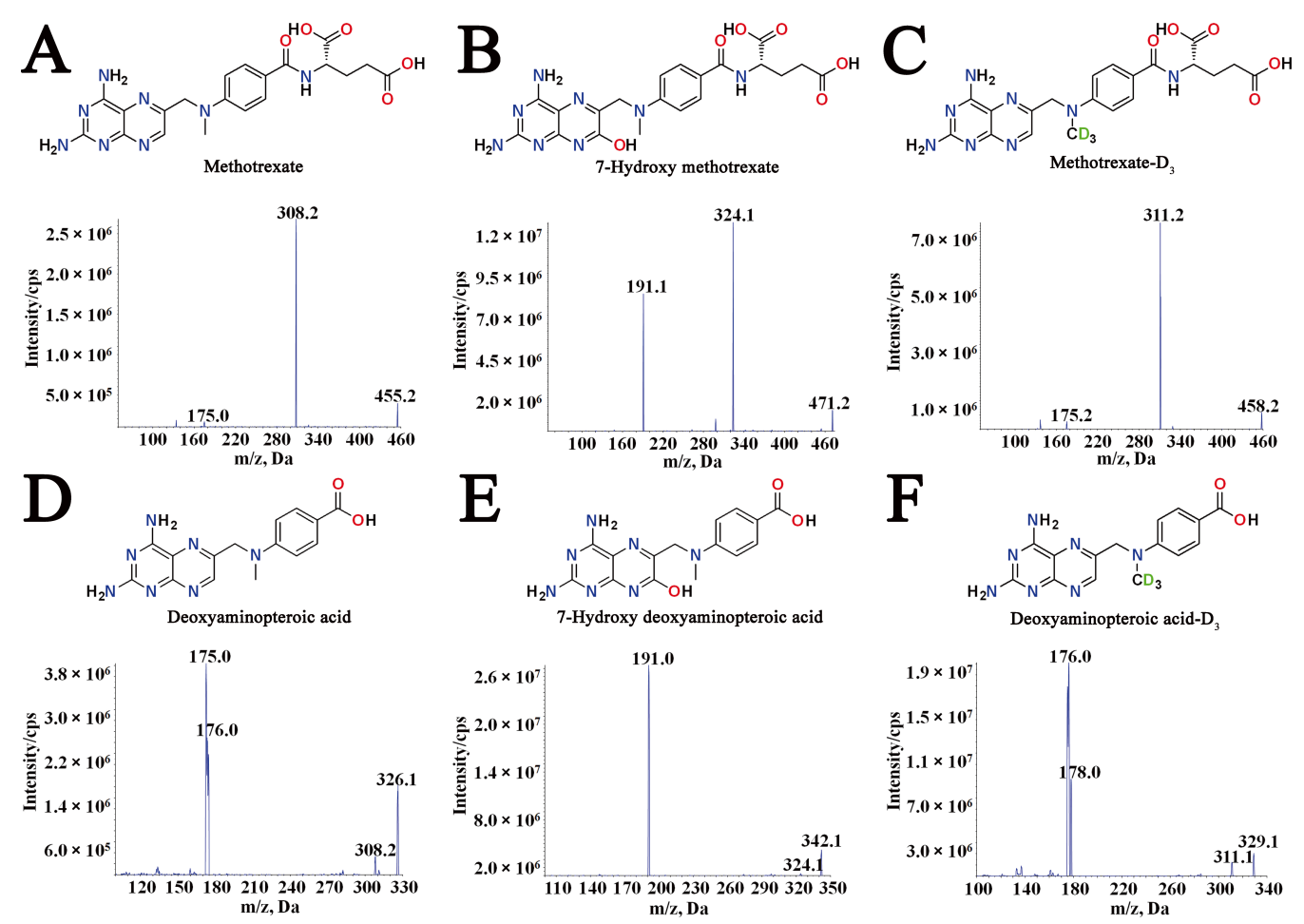

Fig. 1 Chemical structure and mass spectrometry of analytes and internal standards. (A) Methotrexate (about $10 \mathrm{ng} / \mathrm{mL}$ ); (B) 7-hydroxy methotrexate (about $50 \mathrm{ng} / \mathrm{mL}$ ); (C) methotrexate- $\mathrm{D}_{3}$ (about $10 \mathrm{ng} / \mathrm{mL}$ ); (D) deoxyaminopteroic acid (about $10 \mathrm{ng} / \mathrm{mL}$ ); (E) 7-hydroxy deoxyaminopteroic acid (about $50 \mathrm{ng} / \mathrm{mL}$ ); (F) deoxyaminopteroic acid-D 3 (about $10 \mathrm{ng} / \mathrm{mL}$ ).

\section{Selectivity and $L L O Q$}

To evaluate the selectivity, analytes- and IS-free urine from 10 individuals was used. LLOQ was regarded as the lowest concentration of the calibration curve $(0.02 \mu \mathrm{mol} / \mathrm{L}$ for MTX and DAMPA, and $0.1 \mu \mathrm{mol} / \mathrm{L}$ for $7-\mathrm{OH} \mathrm{MTX}$ and $7-\mathrm{OH}$ DAMPA). The selectivity was acceptable when the interfering peak areas in the analytes- and IS-free urine were less than $20 \%$ of the analytes peak areas in the LLOQ sample. For LLOQ samples, the mean bias should be within $\pm 20 \%$, and the withinrun and between-run coefficient of variation $(\mathrm{CV})$ should be less than $20 \% .27,28$

\section{Carry-over and linearity}

To validate the carry-over of the analytes and IS, a blank sample was analyzed immediately following the highest concentration of the calibration sample. The carry-over was acceptable when the peak area of the blank sample was less than $20 \%$ of the peak area of the LLOQ sample for the analytes, ${ }^{28}$ and $5 \%$ for the IS (laboratory standard). The method of weighted least-squares (weighting factor $=1 / x^{2}$ ) was used for linear regression. The bias of each level of the calibrator should be within $\pm 15 \%$ and the correlative coefficient of linear regression function should be higher than 0.995 .

\section{Accuracy and precision}

Five replicates of QC samples at $0.02,0.06,0.12,1.8$, and $3 \mu \mathrm{mol} / \mathrm{L}$ for MTX and DAMPA, and $0.1,0.3,0.6,9$, and $15 \mu \mathrm{mol} / \mathrm{L}$ for 7-OH MTX and 7-OH DAMPA were analyzed to evaluate the intra-day and inter-day accuracy and precision (20 days). The bias and imprecision of QC samples should be within $\pm 15 \%$ ( $\pm 20 \%$ for LLOQ) and less than $15 \%$ (20\% for LLOQ), respectively.

\section{Recovery and matrix effect}

To evaluate the recovery and matrix effect, three batches of QC samples at $0.06,0.12,1.8$, and $3 \mu \mathrm{mol} / \mathrm{L}$ for MTX and DAMPA, and $0.3,0.6,9$, and $15 \mu \mathrm{mol} / \mathrm{L}$ for $7-\mathrm{OH}$ MTX and 7-OH DAMPA were prepared:27,28 (A) analytes and IS in blank urine from 10 different individuals with protein precipitation and extraction, (B) analytes and IS in post-protein precipitated urine matrix from 10 different individuals, (C) analytes and IS in methanol (with $15 \%$ water and $0.1 \%$ formic acid). The ratios of $(A / B) \times 100 \%$ and $(B / C) \times 100 \%$ were defined as the recovery and matrix factor. The ratios of $\left(A_{\text {analyte }} / B_{\text {analyte }}\right) /\left(A_{\mathrm{IS}} / B_{\mathrm{IS}}\right) \times 100 \%$ and $\left(B_{\text {analyte }} / C_{\text {analyte }}\right) /\left(B_{\text {IS }} / C_{\text {IS }}\right) \times 100 \%$ were defined as the IS normalized recovery and matrix factor. At all QC levels, the IS normalized recovery should be consistent, and the IS normalized matrix factor should be precise $(\mathrm{CV}<15 \%))^{27,28}$

\section{Dilution integrity and stability}

To evaluate the dilution integrity, 10-fold and 100-fold dilution of samples by blank urine at 10 and 100 times of the highest QC levels were used for 7-OH MTX and 7-OH DAMPA; 10-, 100-, and 1000-fold dilution of samples at 10, 100, and 1000 times of the highest QC levels were used for DAMPA, and 10-, 100-, 1000-, and 10000-fold dilution of samples at 10, 100, 1000, and 10000 times of the highest QC levels were used for MTX. The bias and precision of diluted samples should be within $\pm 15 \%$ and less than $15 \%$, respectively.

To evaluate the stability of analytes during sample preparation, analysis, and storage, QC samples at $0.06,0.12,1.8$, and $3 \mu \mathrm{mol} / \mathrm{L}$ for MTX and DAMPA, and 0.3, 0.6, 9, and $15 \mu \mathrm{mol} / \mathrm{L}$ for 7-OH MTX and 7-OH DAMPA were measured under various conditions (in urine: $24^{\circ} \mathrm{C}$ for $15 \mathrm{~h}, 4^{\circ} \mathrm{C}$ for $22 \mathrm{~h}$, three freeze-thaw cycles from -80 to 24 , and $-80^{\circ} \mathrm{C}$ for 2 and 4 weeks; post extraction: $24^{\circ} \mathrm{C}$ for $2,6,10,24$, and $113 \mathrm{~h}, 4^{\circ} \mathrm{C}$ for 

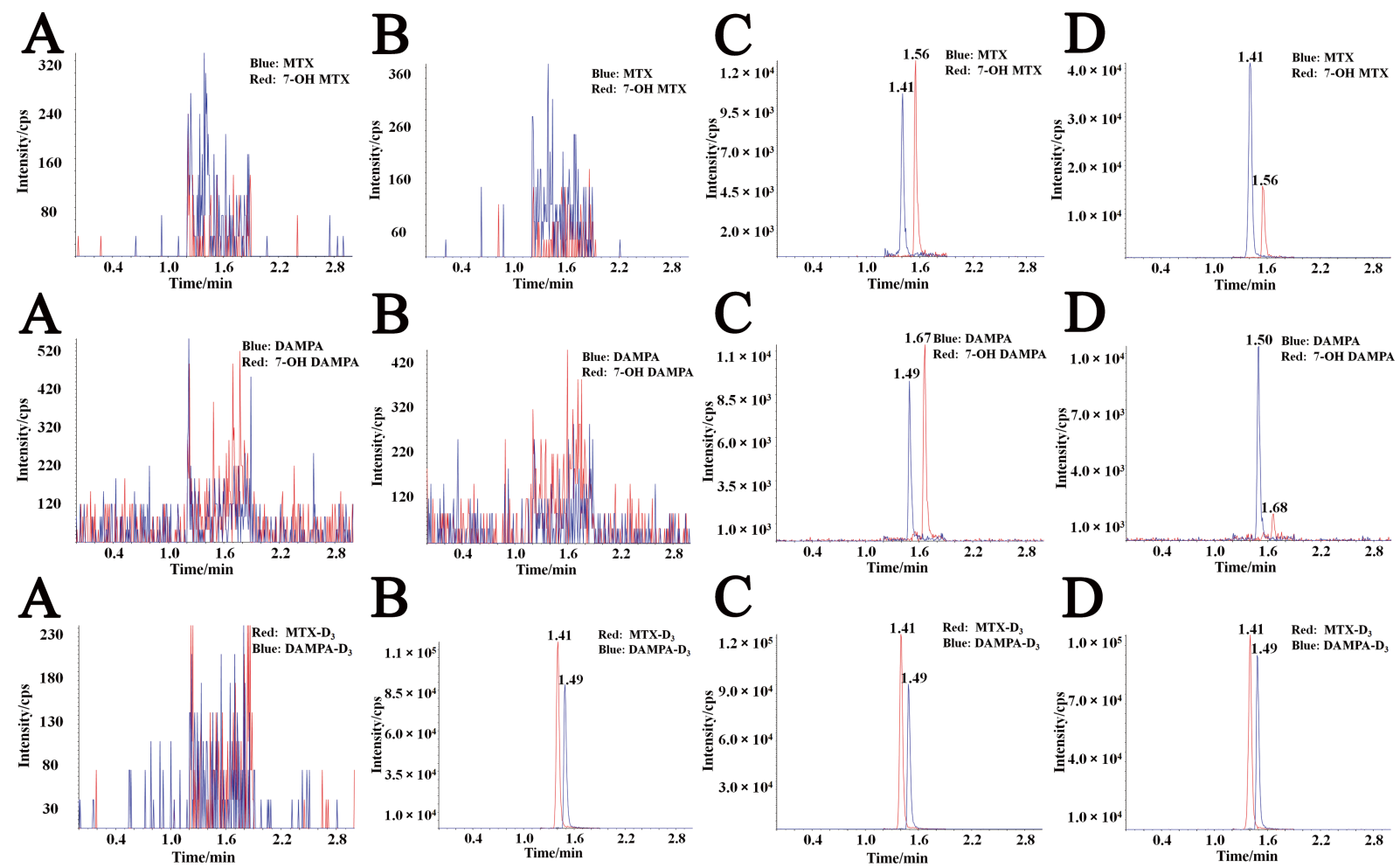

Fig. 2 Typical spectrum of methotrexate (MTX), 7-hydroxy methotrexate (7-OH MTX), deoxyaminopteroic acid (DAMPA) 7-hydroxy deoxyaminopteroic acid (7-OH DAMPA), and internal standard methotrexate- $\mathrm{D}_{3}\left(\mathrm{MTX}-\mathrm{D}_{3}\right)$ and deoxyaminopteroic acid- $\mathrm{D}_{3}\left(\right.$ DAMPA- $\left.\mathrm{D}_{3}\right)$ obtained from: $(\mathrm{A})$ blank plasma; (B) blank plasma only spiked with internal standard; (C) lower limit of quantitation $(0.02 \mu \mathrm{mol} / \mathrm{L}$ for MTX and DAMPA, and $0.1 \mu \mathrm{mol} / \mathrm{L}$ for 7-OH MTX and 7-OH DAMPA); (D) sample from a patient.

$8,12,24$, and $111 \mathrm{~h}, 10^{\circ} \mathrm{C}$ for $10,24,48,72,96$, and $120 \mathrm{~h}$, two freeze-thaw cycles from -80 to 24 , and $-80^{\circ} \mathrm{C}$ for 15 days). Analytes were considered to be stable under a certain condition when the bias of QC samples was within $\pm 15 \%$.

\section{Application}

Patients with primary central nervous system lymphoma receiving high-dose MTX therapy (about $3.5 \mathrm{~g} / \mathrm{m}^{2}$ ) were enrolled. Urine and blood samples were collected at similar time points every morning (about 13, 37, and $61 \mathrm{~h}$ after infusion). Urine concentrations of MTX and its three metabolites were measured by this method, while plasma concentrations of MTX and 7-OH MTX were determined by our previously validated LC-MS/MS method. ${ }^{22}$ The clinical characteristics of enrolled patients including age, sex, height, body weight, body surface area, MTX dose, sampling time, alanine transaminase, serum creatinine, urine volume and urine $\mathrm{pH}$ were recorded.

\section{Statistical analysis}

In this study, urine drug levels were supposed to predict plasma drug levels, which should be normally distributed for multiple linear regression. However, when all plasma drug levels at three sampling time points were analyzed as a whole, its distribution was non-normal even after logarithmic transformation because the plasma drug levels decreased significantly with time. Therefore, the plasma drug levels were separated into three groups according to their sampling time points which was further restricted within $\pm 2 \mathrm{~h}$ to reduce the variance, but each subgroup was still not normally distributed. After a logarithmic transformation, they were normally distributed, except for 7-OH MTX at $13 \mathrm{~h}$ after dosing $(P=$ 0.049). The difference of sampling time between urine and blood varied greatly between individuals, and it was restricted (within $\pm 0.5, \pm 1$, and $\pm 2 \mathrm{~h}$ ) before regression to reduce the bias. The Durbin-Watson test (1.24 to 2.13) indicated that the residuals were independent, and it was another prerequisite for multiple linear regression, which was performed to find out the relationship between the logarithmic transformed plasma drug levels and the covariates (including logarithmic transformed urine drug levels, age, gender, body weight, body surface area, dose, alanine transaminase, and serum creatinine). The influence of urine $\mathrm{pH}(<7$ or $\geq 7)$ on dose-normalized plasma and urine drug levels $\left(\mu \mathrm{mol} / \mathrm{L}\right.$ per $\left.\mathrm{g} / \mathrm{m}^{2}\right)$ was evaluated by a $t$-test or a nonparametric test after restriction of the sampling time $(13.5 \pm 0.5,38 \pm 1$ and $62 \pm 1 \mathrm{~h})$. SPSS software (Ver. 17.0, SPSS Inc., Chicago, USA) was used for statistical analysis including the student's $t$-test, nonparametric test, normality test (Kolmogorov-Smirnov and Shapiro-Wilk test), and multiple linear regression. The statistical significance was defined as $P$ value $<0.05$

\section{Results}

\section{LLOQ and selectivity}

Typical chromatograms of the UHPLC-MS/MS method are shown in Fig. 2. Some peaks were observed at the elution time of analytes and IS; however, their responses were far less than $20 \%$ of the responses of the four analytes at the LLOQ level and $5 \%$ of that of the IS. The two IS did not affect the measurement 
of all analytes. The bias and imprecision of LLOQ samples were -11.40 to 10.10 and $<13.66 \%$ for MTX, -7.00 to 19.50 and $<20.89 \%$ for $7-\mathrm{OH}$ MTX, -8.00 to 9.40 and $<16.59 \%$ for DAMPA, and -12.02 to 6.98 and $<14.20 \%$ for $7-O H$ DAMPA. The signal-to-noise ratio of LLOQ was 57.9 for MTX, 84.8 for 7-OH MTX, 68.2 for DAMPA, and 40.6 for 7-OH DAMPA.

\section{Carry-over and linearity}

There was no carry-over effect for all analytes. The typical linear regression equation is $y=3.32 x+0.0121, r=0.9998$ for MTX, $y=0.651 x+0.00393, r=0.9980$ for 7-OH MTX, $y=$ $4.24 x+0.00218, \quad r=0.9994$ for DAMPA, and $y=1.06 x+$ $0.017, r=0.9991$ for 7-OH DAMPA ( $x$, analytes concentration; $y$, peak area ratio of the analytes to IS).

\section{Accuracy and precision}

Table 1 shows the intra- and inter-day accuracy and precision of the method. At five QC levels, the intra- and inter-day bias and imprecision were -1.30 to 6.81 and $<4.73 \%$ for MTX, -4.02 to 4.47 and $<6.98 \%$ for $7-\mathrm{OH}$ MTX, -8.00 to 7.61 and $<9.04 \%$ for DAMPA, and -5.10 to 3.76 and $<8.92 \%$ for $7-\mathrm{OH}$ DAMPA, respectively.

Recovery and matrix effect

At four QC levels, the IS normalized recovery and matrix factor were 102.59 to $108.72 \%$ and 97.61 to $99.73 \%$ (CV $<4.98 \%$ ) for MTX, 96.03 to $104.97 \%$ and 117.65 to $124.70 \%$ (CV <10.55\%) for 7-OH MTX, 102.05 to $109.49 \%$ and 98.60 to $104.84 \%$ (CV <4.43\%) for DAMPA, and 92.34 to $104.85 \%$ and 156.57 to $172.93 \%(\mathrm{CV}<20.68 \%)$ for $7-\mathrm{OH}$ DAMPA (detail in Table 2).

\section{Dilution integrity and stability}

The bias and imprecision of diluted samples indicated that 10and 100-fold dilution for 7-OH MTX and 7-OH DAMPA, 10-, 100-, and 1000-fold dilution for DAMPA, and 10-, 100-, 1000-, and 10000-fold dilution for MTX did not affect the analysis (data not shown). ${ }^{27,28}$ At four QC levels, MTX, 7-OH MTX, DAMPA, and 7-OH DAMPA were stable under all tested conditions with the bias ranging from -10.53 to $16.00 \%$ (Table S2).

\section{Method application}

A total of 171 urine and blood samples from 38 patients were enrolled and analyzed. DAMPA was observed in 100 urine samples, while 7-OH DAMPA was only observed in 43 urine samples. The clinical characteristics of our patients are summarized in Table S3. In multiple regression, plasma MTX and 7-OH MTX levels increased with the urine drug levels, age, serum creatinine and alanine transaminase. The correlation was poor between urine and blood for MTX and 7-OH MTX at three sampling time points $\left(R^{2}: 0.16\right.$ to 0.51 , detail in Table 3$)$. Therefore we concluded that urine might not replace blood for MTX monitoring. Dose-normalized urine and plasma MTX and 7-OH MTX levels were similar in patients with different urine $\mathrm{pH}$ values $(\mathrm{pH}<7$ or $\geq 7)$. Unexpectedly, at $62 \mathrm{~h}$ after dosing, 7-OH MTX plasma level was higher in patients with urine $\mathrm{pH} \geq 7$ compared to those with urine $\mathrm{pH}<7 \quad(n=19)$ (Table S4).

\section{Discussion}

\section{Method development and validation}

One-step protein precipitation was efficient and simple, ${ }^{25}$ and it was used in our previous methods ${ }^{13,22}$ and many other studies
Table 1 Precision and accuracy for the determination of MTX, 7-OH MTX, DAMPA, and 7-OH DAMPA in human urine

\begin{tabular}{|c|c|c|c|c|}
\hline Measurement & Analyte & $\begin{array}{c}\text { Nominal } \\
\text { concentration/ } \\
\mu \mathrm{M}\end{array}$ & $\begin{array}{c}\text { Bias, } \\
\%\end{array}$ & $\begin{array}{c}\text { Coefficient of } \\
\text { variation, } \\
\%\end{array}$ \\
\hline \multirow{20}{*}{$\begin{array}{l}\text { Intra-day, } \\
n=5\end{array}$} & \multirow[t]{5}{*}{ MTX } & 0.02 & -1.30 & 3.16 \\
\hline & & 0.06 & 6.67 & 1.65 \\
\hline & & 0.12 & 1.67 & 2.96 \\
\hline & & 1.8 & 0.74 & 1.77 \\
\hline & & 3 & -0.22 & 1.07 \\
\hline & \multirow[t]{5}{*}{ 7-OH MTX } & 0.1 & -4.02 & 3.22 \\
\hline & & 0.3 & -1.33 & 6.98 \\
\hline & & 0.6 & 3.83 & 3.29 \\
\hline & & 9 & 3.33 & 5.17 \\
\hline & & 15 & 0.89 & 2.75 \\
\hline & \multirow[t]{5}{*}{ DAMPA } & 0.02 & -8.00 & 9.04 \\
\hline & & 0.06 & 7.61 & 1.85 \\
\hline & & 0.12 & 0.28 & 0.48 \\
\hline & & 1.8 & 5.37 & 0.81 \\
\hline & & 3 & 1.67 & 4.19 \\
\hline & \multirow[t]{5}{*}{ 7-OH DAMPA } & 0.1 & -5.10 & 8.92 \\
\hline & & 0.3 & 0.78 & 7.65 \\
\hline & & 0.6 & -1.28 & 2.58 \\
\hline & & 9 & 2.15 & 1.21 \\
\hline & & 15 & -0.89 & 3.70 \\
\hline \multirow{20}{*}{$\begin{array}{c}\text { Inter-day, } \\
n=20\end{array}$} & \multirow[t]{5}{*}{ MTX } & 0.02 & -0.46 & 4.32 \\
\hline & & 0.06 & 6.81 & 4.73 \\
\hline & & 0.12 & 5.19 & 3.36 \\
\hline & & 1.8 & 2.13 & 2.33 \\
\hline & & 3 & -0.99 & 1.97 \\
\hline & \multirow[t]{5}{*}{ 7-OH MTX } & 0.1 & 0.20 & 6.21 \\
\hline & & 0.3 & 2.59 & 5.14 \\
\hline & & 0.6 & 4.47 & 5.03 \\
\hline & & 9 & 0.95 & 4.31 \\
\hline & & 15 & -1.67 & 3.67 \\
\hline & \multirow{5}{*}{ DAMPA } & 0.02 & -0.06 & 4.91 \\
\hline & & 0.06 & 4.38 & 3.35 \\
\hline & & 0.12 & 4.24 & 2.96 \\
\hline & & 1.8 & 2.58 & 3.02 \\
\hline & & 3 & -0.34 & 2.06 \\
\hline & \multirow[t]{5}{*}{ 7-OH DAMPA } & 0.1 & -1.86 & 5.31 \\
\hline & & 0.3 & 0.98 & 4.63 \\
\hline & & 0.6 & 3.76 & 4.17 \\
\hline & & 9 & 2.07 & 3.77 \\
\hline & & 15 & -1.20 & 3.42 \\
\hline
\end{tabular}

Abbreviations: MTX, methotrexate; 7-OH MTX, 7-hydroxy methotrexate; DAMPA, deoxyaminopteroic acid; 7-OH DAMPA, 7-hydroxy deoxyaminopteroic acid.

for MTX analysis. ${ }^{14,17,24,26}$ However, a pretreatment by pure methanol resulted in an asymmetric peak for 7-OH DAMPA. To solve this problem, various proportions of water $(10,15,20$, and $25 \%$ ) were added in methanol for protein precipitation, and symmetric peaks were obtained when the water proportion was equal to or higher than $15 \%$. Therefore methanol containing $15 \%$ water was used for protein precipitation, but some precipitates were observed at the bottom of the supernatants of the post-extracted samples after storing at $10^{\circ} \mathrm{C}$ for $10 \mathrm{~min}$ or longer. To solve this problem, the post-extracted samples were stored at $4^{\circ} \mathrm{C}$ for a period of time $(10,20,30$, and $40 \mathrm{~min})$ for complete formation of the precipitates, and following a 2-min centrifugation at $12000 \times g$ to remove it. The results indicated that storing at $4^{\circ} \mathrm{C}$ for $30 \mathrm{~min}$ was efficient for complete formation of the precipitates, and it was used in the present study. Leading and tailing peaks were observed when the injection volume was higher than $2.5 \mu \mathrm{L}$. Therefore, a $2-\mu \mathrm{L}$ 
Table 2 The recovery and matrix effect of MTX, 7-OH MTX, DAMPA, and 7-OH DAMPA in human urine (mean \pm standard deviation, $n=10)$

\begin{tabular}{|c|c|c|c|c|c|c|c|c|c|}
\hline Drug & $\begin{array}{c}\text { Nominal } \\
\text { concentration/ } \\
\mu \mathrm{M}\end{array}$ & $\begin{array}{c}\text { Recoveries } \\
\text { of analytes, } \\
\%\end{array}$ & $\begin{array}{c}\text { Recoveries } \\
\text { of IS, } \\
\%\end{array}$ & $\begin{array}{c}\text { IS normalized } \\
\text { recoveries, } \\
\%\end{array}$ & $\begin{array}{c}\mathrm{CV} \text { of IS } \\
\text { normalized } \\
\text { recoveries, \% }\end{array}$ & $\begin{array}{c}\text { Matrix factor } \\
\text { of analytes, } \\
\%\end{array}$ & $\begin{array}{c}\text { Matrix } \\
\text { factor of IS, } \\
\%\end{array}$ & $\begin{array}{c}\text { IS normalized } \\
\text { matrix factor, } \\
\%\end{array}$ & $\begin{array}{c}\mathrm{CV} \text { of IS } \\
\text { normalized } \\
\text { matrix factor, \% }\end{array}$ \\
\hline \multirow[t]{4}{*}{ MTX } & 0.06 & $102.7 \pm 6.7$ & $94.5 \pm 2.5$ & $108.7 \pm 7.4$ & 6.81 & $95.6 \pm 6.2$ & $97.7 \pm 6.8$ & $97.9 \pm 4.9$ & 4.98 \\
\hline & 0.12 & $103.1 \pm 6.2$ & $100.6 \pm 3.9$ & $102.6 \pm 6.8$ & 6.68 & $101.4 \pm 5.8$ & $103.5 \pm 7.0$ & $98.1 \pm 2.9$ & 2.99 \\
\hline & 1.8 & $101.3 \pm 4.1$ & $97.2 \pm 2.4$ & $104.3 \pm 5.1$ & 4.93 & $94.6 \pm 7.6$ & $97.0 \pm 7.4$ & $97.6 \pm 3.2$ & 3.32 \\
\hline & 3 & $101.6 \pm 5.8$ & $97.1 \pm 5.2$ & $104.7 \pm 4.5$ & 4.28 & $105.3 \pm 6.0$ & $105.6 \pm 6.1$ & $99.7 \pm 1.8$ & 1.76 \\
\hline \multirow[t]{4}{*}{ 7-OH MTX } & 0.3 & $99.2 \pm 7.6$ & $94.5 \pm 2.5$ & $105.0 \pm 7.3$ & 6.94 & $119.5 \pm 6.1$ & $97.7 \pm 6.8$ & $123.0 \pm 13.0$ & 10.55 \\
\hline & 0.6 & $96.5 \pm 9.1$ & $100.6 \pm 3.9$ & $96.0 \pm 10.3$ & 10.70 & $128.3 \pm 5.8$ & $103.5 \pm 7.0$ & $124.7 \pm 11.9$ & 9.53 \\
\hline & 9 & $101.4 \pm 9.8$ & $97.2 \pm 2.4$ & $104.3 \pm 10.3$ & 9.87 & $113.5 \pm 4.7$ & $97.0 \pm 7.4$ & $117.8 \pm 12.1$ & 10.24 \\
\hline & 15 & $100.5 \pm 5.2$ & $97.1 \pm 5.2$ & $103.7 \pm 5.0$ & 4.79 & $123.8 \pm 6.2$ & $105.6 \pm 6.1$ & $117.6 \pm 9.7$ & 8.28 \\
\hline \multirow[t]{4}{*}{ DAMPA } & 0.06 & $102.4 \pm 4.2$ & $93.5 \pm 2.8$ & $109.5 \pm 4.7$ & 4.29 & $71.7 \pm 10.5$ & $68.7 \pm 11.6$ & $104.8 \pm 4.6$ & 4.43 \\
\hline & 0.12 & $103.0 \pm 4.5$ & $99.3 \pm 3.1$ & $103.8 \pm 5.2$ & 5.04 & $71.9 \pm 10.6$ & $73.3 \pm 12.7$ & $98.6 \pm 4.3$ & 4.37 \\
\hline & 1.8 & $100.6 \pm 5.2$ & $98.7 \pm 3.0$ & $102.0 \pm 6.1$ & 5.96 & $69.1 \pm 11.9$ & $68.6 \pm 12.1$ & $101.0 \pm 3.6$ & 3.59 \\
\hline & 3 & $99.6 \pm 6.9$ & $95.0 \pm 7.2$ & $105.0 \pm 4.7$ & 4.51 & $77.4 \pm 10.6$ & $76.3 \pm 10.4$ & $101.5 \pm 1.6$ & 1.56 \\
\hline \multirow[t]{4}{*}{ 7-OH DAMPA } & 0.3 & $98.1 \pm 7.4$ & $93.5 \pm 2.8$ & $104.8 \pm 7.5$ & 7.19 & $114.5 \pm 5.5$ & $68.7 \pm 11.6$ & $171.4 \pm 33.0$ & 19.25 \\
\hline & 0.6 & $91.5 \pm 9.2$ & $99.3 \pm 3.1$ & $92.3 \pm 10.4$ & 11.28 & $123.0 \pm 11.3$ & $73.3 \pm 12.7$ & $172.9 \pm 35.8$ & 20.68 \\
\hline & 9 & $101.1 \pm 5.2$ & $98.7 \pm 3.0$ & $102.5 \pm 5.6$ & 5.46 & $104.4 \pm 3.1$ & $68.6 \pm 12.1$ & $156.6 \pm 28.3$ & 18.07 \\
\hline & 15 & $97.9 \pm 5.6$ & $95.0 \pm 7.2$ & $103.3 \pm 4.2$ & 4.04 & $117.7 \pm 4.2$ & $76.3 \pm 10.4$ & $157.5 \pm 26.6$ & 16.86 \\
\hline
\end{tabular}

Abbreviations: MTX, methotrexate; 7-OH MTX, 7-hydroxy methotrexate; DAMPA, deoxyaminopteroic acid; 7-OH DAMPA, 7-hydroxy deoxyaminopteroic acid; IS, internal standard (MTX-D 3 for MTX and 7-OH MTX, DAMPA-D 3 for DAMPA and 7-OH DAMPA); CV, coefficient of variation.

Table 3 Multiple linear regression results between logarithmic transformed plasma drug levels and covariates (the blood sampling time was restricted within $\pm 2 \mathrm{~h}$, and the difference of sampling time between blood and urine was restricted within $\pm 1 \mathrm{~h}$ )

\begin{tabular}{|c|c|c|c|c|c|c|c|c|}
\hline $\begin{array}{l}\text { Time } \\
\text { after } \\
\text { dose/h }\end{array}$ & $\begin{array}{c}\text { Logarithmic } \\
\text { transformed } \\
\text { plasma drug } \\
\text { levels }\end{array}$ & $\begin{array}{c}\text { Normality of } \\
\text { logarithmic } \\
\text { transformed plasma } \\
\text { drug levels }\end{array}$ & $\begin{array}{c}\text { Goodness } \\
\text { of fit, } R^{2}\end{array}$ & $\begin{array}{c}\text { Equation } \\
\text { significance } \\
(F \text { test })\end{array}$ & $\begin{array}{l}\text { Covariates and its } \\
\text { standardized } \\
\text { coefficient }\end{array}$ & $\begin{array}{l}\text { Significance of } \\
\text { standardized } \\
\text { coefficient }(t \text {-test) }\end{array}$ & $\begin{array}{c}\text { Residual } \\
\text { independence } \\
\text { (Durbin- } \\
\text { Watson test) }\end{array}$ & $\begin{array}{l}\text { Normality } \\
\text { of residual }\end{array}$ \\
\hline \multirow[t]{4}{*}{13} & MTX & 0.94 & 0.51 & $<0.001$ & Age (0.47) & $<0.001$ & 1.55 & 0.61 \\
\hline & & & & & SCR (0.38) & 0.001 & & \\
\hline & & & & & $\operatorname{ALT}(0.30)$ & 0.009 & & \\
\hline & 7-OH MTX & 0.049 & 0.16 & 0.005 & $\operatorname{ALT}(0.40)$ & 0.005 & 1.52 & 0.0080 \\
\hline \multirow[t]{4}{*}{37} & MTX & 0.55 & 0.22 & 0.017 & MTXU (0.35) & 0.031 & 2.02 & 0.99 \\
\hline & & & & & $\operatorname{ALT}(0.32)$ & 0.047 & & \\
\hline & 7-OH MTX & 0.79 & 0.34 & 0.001 & 7-OH MTXU (0.46) & 0.003 & 1.24 & 0.66 \\
\hline & & & & & $\operatorname{ALT}(0.32)$ & 0.031 & & \\
\hline \multirow[t]{2}{*}{61} & MTX & 0.11 & 0.34 & 0.004 & MTXU (0.59) & 0.004 & 1.38 & 0.25 \\
\hline & 7-OH MTX & 0.18 & 0.21 & 0.031 & $\operatorname{ALT}(0.46)$ & 0.031 & 2.13 & 0.40 \\
\hline
\end{tabular}

Abbreviations: MTX, methotrexate; 7-OH MTX, 7-hydroxy methotrexate; SCR, serum creatinine; ALT, alanine transaminase; MTXU,

logarithmic transformed urine methotrexate levels; 7-OH MTXU, logarithmic transformed urine 7-hydroxy methotrexate levels.

injection volume was used for analysis, which was comparable to those in published studies $(0.5$ to $2 \mu \mathrm{L}){ }^{13,17,18,22,23}$ The HPLC conditions were similar to our previously published studies with minor modifications, including an extension of the gradient elution time (from 0.5 to $1 \mathrm{~min}$ ) for complete separation of the four analytes and a reduction of the column washing time (from 0.8 to $0.6 \mathrm{~min}$ ). ${ }^{13,22}$ The 3 -min run time was much shorter than those in many published methods (5.52 to $6.6 \mathrm{~min}$ ) for the analysis of MTX and its metabolites, ${ }^{2,15,24}$ and close to two studies (3.0 and $3.6 \mathrm{~min}$ ) for MTX analysis. ${ }^{18,20}$

The recovery and matrix factor of analytes were comparable to the observations in published studies in various biological fluids including human urine, plasma, serum, and cerebrospinal fluid (recovery: 72 to $126 \%$ for MTX, 67 to $122 \%$ for $7-\mathrm{OH}$ MTX, and 54.4 to $105.1 \%$ for DAMPA; matrix factor: 70.5 to $118 \%$ for MTX, 90 to $105 \%$ for 7-OH MTX, and 101 to $107 \%$ for DAMPA). ${ }^{2,3,15-18,23,24,26}$ The possible reasons for the matrix induced response enhancement for both 7-OH MTX (117.65 to $124.70 \%$ ) and 7-OH DAMPA (156.57 to $172.93 \%$ ), and the big inter-individual variance of 7-OH DAMPA matrix factor (CV $<20.68 \%$ ) were summarized as follows: (1) the one-step protein precipitation for sample extraction retained many matrix in the post-extracted samples, ${ }^{29,30}$ (2) the fast separation procedure of the HPLC method could not efficiently separate all of the matrix from the analytes; ${ }^{30,31}$ (3) MTX-D ${ }_{3}$ and DAMPA-D ${ }_{3}$ were used for the quantitation of 7-OH MTX and 7-OH DAMPA, respectively. However, the chemical structures and retention times were different between the two internal standards and the two analytes, therefore their matrix effects could not be well compensated. ${ }^{30}$ The matrix effects of both 7-OH MTX and 7-OH DAMPA might be well compensated by using an efficient sample purification technology, such as solid-phase extraction, an efficient separation procedure, and/or the isotope internal standards. ${ }^{29-31}$ All analytes were stable in urine and 
post-extracted urine matrix under tested conditions, which was consistent with the results in previous studies. . $^{2,3,15-17,21,23,24}$

\section{Method application}

Before multiple regression, plasma drug levels were separated into three groups according to their sampling time points, which was restricted within $\pm 2 \mathrm{~h}$. Moreover, the difference of the sampling time between urine and blood was also restricted (within $\pm 0.5, \pm 1$, and $\pm 2 \mathrm{~h}$ ), and within $\pm 1 \mathrm{~h}$ was the best to reduce the variance and to ensure the normal distribution of the data. The multiple-regression results indicated that the plasma drug levels increased with the urine drug levels, age, serum creatinine and alanine transaminase. MTX was mainly excreted in the urine, ${ }^{1}$ which could explain the correlation between increased plasma MTX levels and elevated urine MTX levels. Interestingly, the urine 7-OH MTX levels increased with the plasma 7-OH MTX levels at $37 \mathrm{~h}$ after dosing, although urine was the minor route for 7-OH MTX excretion. ${ }^{32,33}$ Plasma MTX levels increased with serum creatinine at $13 \mathrm{~h}$ after dosing, which was caused by the reduced urine drug excretion due to impaired renal function. ${ }^{11}$ Moreover, the renal function decreased with age, which could explain that the plasma MTX levels increased with age at $13 \mathrm{~h}$ after dosing. MTX and 7-OH MTX plasma levels increased with alanine transaminase, which could be elucidated by the following reasons: both MTX and 7-OH MTX were transformed into their polyglutamates mainly via folypolyglutamate synthase in the liver;34,35 these polyglutamates could not be transported out of the cells when the number of their glutamate residues was greater than three, which resulted in significant accumulation of these polyglutamates in the liver; ${ }^{35,36}$ in the case of liver injury, these polyglutamates were released into the blood with the death of hepatocyte and transformed back into MTX and 7-OH MTX via blood gamma-glutamyl hydrolase..$^{22,37}$ In the present study, due to a poor correlation between the urine and blood drug levels, urine could not replace blood for MTX monitoring in patients receiving high-dose MTX therapy.

Alkalinization was routinely performed for patients receiving high-dose MTX therapy to enhance the renal excretion of MTX and to reduce toxicity risk. ${ }^{8,9}$ In the present study, dosenormalized plasma and urine levels of both MTX and 7-OH MTX varied greatly between individuals (Table S4), which could be explained by the following reasons: the small sample size; the different MTX dose, sampling time, urine volume, patients' physiological status and pharmacokinetic parameters of analytes between individuals. ${ }^{11}$ The dose-normalized plasma and urine MTX and 7-OH MTX levels were similar between patients with different urine $\mathrm{pH}(<7$ or $\geq 7)$, which might be explained by the similar alkalinization treatment of enrolled patients. Dose-normalized 7-OH MTX plasma level was higher in patients with the urine $\mathrm{pH} \geq 7$ compared to those with the urine $\mathrm{pH}<7$ at $62 \mathrm{~h}$ after dosing. This unexpected result might be also explained by the reasons given for the big variance of the drug levels between individuals.

\section{Deficiencies of the study}

(1) The results in the present study should be treated with caution due to the great inter-individual variance of the drug levels in both blood and urine. (2) The sample size was small. (3) The sampling time between urine and blood was different. (4) The influence of the renal and liver function on the urine drug levels was not evaluated due to lack of cases (9 samples with slight renal impairment; 10 samples with slight liver impairment). (5) The influence of co-medications on the urine drug levels was not evaluated.

\section{Conclusions}

An accurate and robust UHPLC-MS/MS method for simultaneous determination of MTX, 7-OH MTX, DAMPA, and 7-OH DAMPA in urine was developed, validated, and applied in clinical practice. The simple and efficient (recovery 92.34 to $109.49 \%$ ) one-step protein precipitation for sample pretreatment and the short analysis time $(3 \mathrm{~min})$ were suitable for clinical application. The calibration range (expanded by dilution factors) could cover most of the clinical samples. The interindividual variance of matrix factor for all analytes $(<20.68 \%)$ could ensure the accuracy of analysis. All processes during sample collection, pretreatment, and storage did not affect the analysis. Plasma MTX and 7-OH MTX levels increased with urine drug levels, age, serum creatinine and alanine transaminase, all of which should be considered in clinical practice. Urine might not replace blood for MTX monitoring due to their poor correlation $\left(R^{2}, 0.16\right.$ to 0.51$)$. Urine $\mathrm{pH}(<7$ or $\geq 7)$ did not affect dose-normalized urine and plasma MTX and 7-OH MTX levels, but these results did not mean that alkalinization is not important for patients receiving high-dose MTX therapy. In fact, alkalinization is a key strategy for toxicity prevention in patients receiving high-dose MTX therapy. Due to the deficiencies of the study, these findings should be treated with caution and further and larger studies are warranted to confirm these results.

\section{Acknowledgements}

Thanks are given to our patients and nurses. This work was supported by the Beijing Municipal Administration of Hospitals (ZYLX201827) and Beijing Municipal Health Bureau (2018000021469G238).

\section{Supporting Information}

This material is available free of charge on the Web at http:// www.jsac.or.jp/analsci/.

\section{References}

1. Hospira, Label for Methotrexate Injection, http://www. accessdata.fda.gov/drugsatfda_docs/label/2011/011719s 117lbl.pdf2011.

2. R. C. Schofield, L. V. Ramanathan, K. Murata, M. Grace, M. Fleisher, M. S. Pessin, and D. C. Carlow, J. Chromatogr. $B, \mathbf{2 0 1 5}, 1002,169$.

3. M. Uchiyama, T. Matsumoto, T. Matsumoto, S. Jimi, Y. Takamatsu, K. Tamura, and S. Hara, Biomed. Chromatogr., 2012, 26, 76.

4. F. Berga, P. Luna, C. Martorell, J. Rey, I. Gomila, S. Gimenez, A. Costa-Bauza, M. A. Elorza, I. Sanchez, F. Grases, and B. Barcelo, Clin. Chim. Acta, 2018, 487, 1.

5. E. Klapkova, J. Kukacka, K. Kotaska, I. Suchanska, R. Urinovska, and R. Prusa, Clin. Lab., 2011, 57, 599.

6. S. A. Jacobs, R. G. Stoller, B. A. Chabner, and D. G. Johns, J. Clin. Invest., 1976, 57, 534.

7. L. B. Ramsey, F. M. Balis, M. M. O’Brien, K. Schmiegelow, J. L. Pauley, A. Bleyer, B. C. Widemann, D. Askenazi, S. Bergeron, A. Shirali, S. Schwartz, A. A. Vinks, and J. Heldrup, Oncologist, 2018, 23, 52. 
8. T. E. Sand and S. Jacobsen, Eur. J. Clin. Pharmacol., 1981, 19, 453.

9. O. Mir, S. Ropert, A. Babinet, J. Alexandre, F. Larousserie, J. P. Durand, E. Enkaoua, P. Anract, and F. Goldwasser, Cancer Chemother. Pharmacol., 2010, 66, 1059.

10. S. A. Drost, J. R. Wentzell, P. Giguere, D. L. McLurg, M. Sabloff, S. Kanji, and T. T. Nguyen, Pharmacotherapy, 2017, 37, 684.

11. S. Mei, X. Li, X. Jiang, K. Yu, S. Lin, and Z. Zhao, J. Pharm. Sci., 2018, 107, 1454.

12. J. B. Oudart, B. Marquet, C. Feliu, C. Gozalo, Z. Djerada, and H. Millart, Ann. Biol. Clin., 2016, 74, 333.

13. S. Mei, L. Zhu, X. Li, J. Wang, X. Jiang, H. Chen, J. Huo, L. Yang, S. Lin, and Z. Zhao, Anal. Sci., 2017, 33, 665.

14. R. C. Schofield, L. V. Ramanathan, K. Murata, M. Fleisher, M. S. Pessin, and D. C. Carlow, Methods Mol. Biol., 2016, 1383, 213.

15. M. S. Roberts, N. S. Selvo, J. K. Roberts, V. M. Daryani, T. S. Owens, K. E. Harstead, A. Gajjar, and C. F. Stewart, J. Liq. Chromatogr. Relat. Technol., 2016, 39, 745.

16. M. A. Al-Ghobashy, S. A. Hassan, D. H. Abdelaziz, N. M. Elhosseiny, N. A. Sabry, A. S. Attia, and M. H. El-Sayed, J. Chromatogr. B, 2016, 1038, 88.

17. D. Wu, Y. Wang, Y. Sun, N. Ouyang, and J. Qian, Biomed. Chromatogr., 2015, 29, 1197.

18. C. C. Christianson, C. J. Johnson, and S. R. Needham, Bioanalysis, 2013, 5, 1387.

19. R. Bouquié, G. Deslandes, B. N. Bernáldez, C. Renaud, E. Dailly, and P. Jolliet, Anal. Methods, 2013, 6, 178.

20. E. den Boer, S. G. Heil, B. D. van Zelst, R. J. Meesters, B. C. Koch, M. L. Te Winkel, M. M. van den Heuvel-Eibrink, T. M. Luider, and R. de Jonge, Ther. Drug Monit., 2012, 34, 432

21. H. L. Cheng, S. S. Chiou, Y. M. Liao, C. Y. Lu, Y. L. Chen, and S. M. Wu, Anal. Bioanal. Chem., 2010, 398, 2183.

22. S. Mei, X. Shi, Y. Du, Y. Cui, C. Zeng, X. Ren, K. Yu, Z. Zhao, and S. Lin, J. Pharm. Biomed. Anal., 2018, 158, 300.

23. A. Barbieri, L. Sabatini, P. Indiveri, R. Bonfiglioli, V. Lodi,

and F. S. Violante, Rapid Commun. Mass Spectrom., 2006 , 20,1889

24. J. Bluett, I. Riba-Garcia, K. Hollywood, S. M. Verstappen, A. Barton, and R. D. Unwin, Analyst, 2015, 140, 1981.

25. G. Fabrizi, M. Fioretti, and L. Mainero Rocca, Biomed. Chromatogr., 2016, 30, 1297.

26. P. Koufopantelis, S. Georgakakou, M. Kazanis, C. Giaginis, A. Margeli, S. Papargiri, and I. Panderi, J. Chromatogr. B, 2009, 877, 3850

27. EMEA, Committee for Medicinal Products for Human Use, Guideline on Bioanalytical Method Validation, EMEA/ CHMP/EWP/192217/2009 Rev. 1 Corr. 2** (21 July 2011), http://www.ema.europa.eu/docs/en_GB/document_library/ Scientific_guideline/2011/08/WC500109686.pdf2011.

28. FDA, Guidance for Industry: Bioanalytical Method Validation, https://www.fda.gov/media/70858/download2018.

29. H. Jiang, H. Cao, Y. Zhang, and D. M. Fast, J. Chromatogr. $B, \mathbf{2 0 1 2}, 891-892,71$.

30. N. R. Srinivas, Biomed. Chromatogr., 2011, 25, 740.

31. L. Hu, J. E. Agbokponto, L. Ding, B. Liu, F. Shi, and C. Gong, Biomed. Chromatogr, 2015, 29, 53.

32. B. Winograd, R. J. Lippens, M. J. Oosterbaan, M. J. Dirks, T. B. Vree, and E. van der Kleijn, Eur. J. Clin. Pharmacol., 1986, 30, 231.

33. P. Bore, A. Iliadis, J. Catalin, S. Just, and J. P. Cano, Cancer Drug Deliv., 1987, 4, 177.

34. T. S. Mikkelsen, C. F. Thorn, J. J. Yang, C. M. Ulrich, D. French, G. Zaza, H. M. Dunnenberger, S. Marsh, H. L. McLeod, K. Giacomini, M. L. Becker, R. Gaedigk, J. S. Leeder, L. Kager, M. V. Relling, W. Evans, T. E. Klein, and R. B. Altman, Pharmacogenet. Genomics, 2011, 21, 679.

35. A. K. Fotoohi and F. Albertioni, Leuk. Lymphoma, 2008 , $49,410$.

36. D. French, W. Yang, C. Cheng, S. C. Raimondi, C. G. Mullighan, J. R. Downing, W. E. Evans, C. H. Pui, and M. V. Relling, Blood, 2009, 113, 4512.

37. S. Inoue, M. Hashiguchi, S. Kawai, and M. Mochizuki, Yakugaku Zasshi, 2009, 129, 1001. 